\title{
Implementing Feminist Pedagogy in ELT by means of tranforming the way you teach and your students learn. Moving forward towards an anti- hierarchical education
}

\author{
Ricardo Ignacio Elizalde González \\ Universidad Bernardo O’Higgins \\ Universidad de Chile
}

\begin{abstract}
.
This paper will review the research conducted on Feminist Pedagogy in the ELT field. In order to carry out this investigation, I inteded to shed light into 7 Chilean feminist EFL university professors who applied feminist pedagogy on a daily basis within their courses. This research seeks to address "the what and how" feminist university professors taught in the EFL univerisity classrooms. Firstly, I observed their classrooms environments, methodologies, students' behaviour, professors' lunchroom, comments and their daily notes as the core and backbone data which ended up being the pedagogical trigger of this research.

In accordance with the data gathering process, it consisted of interviews, openended questionnaires, voice recordings and e-mails. On the other hand, the final results evidenced and demonstrated a wide variety of implementations of feminist pedagogy in EFL contexts. Such application was laborious, arduous and, at the same time, paradoxical and conflicting. As it was revealed in the results, there was no clear methodological pattern to be followed among them methodologically speaking. Thus, professors who participated in this study not only taught about the feminist movement and its story, but also taught it in a very direct and unambiguous way in English which caused great debates and stunning pedagogical outcomes in the way they teach in their own educational scenarios. Regarding to EFL activities they included in their class, it was seen that they have a strong influence and impact on gender equality, feminist pedagogy principles, critical thinking, multicultural education among many others. To summarize, the discussion section of this research deals with the implications of further research on the field of feminist classroom practices, critical pedagogical thinking and multicultural education.
\end{abstract}

Keywords: gender equality, feminist pedagogy principles, critical thinking, multicultural education 